\title{
The development trend and prospect of automobile energy- saving standard system under the goal of peak carbon dioxide emissions
}

\author{
Zheng Tianlei ${ }^{1, a}$, Wang Zhao ${ }^{1}$, Liu Shaohui ${ }^{1}$, Bao Xiang ${ }^{1}$, Liu Zhichao ${ }^{1}$ and Ji Mengxue ${ }^{1}$ \\ ${ }^{1}$ Auto Standardization Research Institute, China Automotive Technology and Research Center Co.,Ltd., Tianjin, 300300, China
}

\begin{abstract}
This paper conducts research on the development trend of automobile energy-saving standard system under China's goal of peak carbon dioxide emissions by 2030. The research first sorted out the carbon dioxide emission standards and regulations of major automobile developed countries in the world, systematically analyzed the current status of China's automobile energy-saving standard system, and proposed the key problems at this stage. With the goal of peak carbon dioxide emissions as the core, the key tasks for the next phase of the construction of the automotive energy-saving standard system are proposed, including comprehensively promoting the formulation of fuel consumption standards for passenger cars and commercial vehicles from 2025 to 2030, and accelerating the construction of NEV energy-saving standard system.
\end{abstract}

\section{Introduction}

China proposes to strive to reach the peak of carbon dioxide emissions by 2030 , and strive to achieve carbon neutrality by 2060. Carbon emissions have become a problem that China's economic development must face in the future. China's automobile industry has developed rapidly in recent years, with rapid growth in production, sales, and ownership. At present, the vehicle ownership structure in China is still dominated by traditional vehicles. The carbon dioxide produced by the consumption of fossil energy such as gasoline and diesel during the use of vehicles has become one of the main sources of carbon emissions in China. China's automobile energy-saving standards have played an important role in promoting the development of energysaving technologies and reducing carbon dioxide emissions by improving the level of automobile fuel economy. In the next stage, China's automobile industry will take the carbon peak before 2030 as the overall development to build an automobile energy-saving standard system with stricter indicators and more complete testing methods.

\section{Domestic and foreign trends}

\subsection{International trend}

In response to global climate change and energy shortages, major developed countries in the automotive industry such as Europe and Japan have introduced a series of automotive fuel consumption or carbon dioxide emission standards and have been continuously tightening them to promote the development of domestic automotive energy-saving technologies, improve automotive fuel economy and consolidate the international competitiveness of the country's auto industry.

The European Union passed Regulation (EU) No. 2019/631 in 2019, setting carbon dioxide emission standards for new passenger cars in the European Union. The regulation has been implemented since January 2020 and proposes to reduce carbon dioxide emissions by 2021 by $15 \%$ from 2025 and $37.5 \%$ from 2030 onwards ${ }^{1}$.

Japan issued a new phase of fuel economy standards for passenger cars in March 2020. The goal is to achieve an average fuel economy of $25.4 \mathrm{~km} / \mathrm{L}$ for passenger cars by 2030 , which is $20 \%$ more stringent than the 2020 standard. Compared with the previous version of the standard, in 2030, when the average fuel economy of passenger cars is calculated, new energy vehicles (referred to as NEV) will be included, and the incentives of NEV has been increased ${ }^{2}$.

\subsection{China's related plans}

In September 2020, China proposed the overall climate action goal of striving for carbon peaks by 2030 and carbon neutrality by 2060 . For healthy and sustainable development, China's automobile industry has issued and implemented a series of automobile energy-saving related policy plans such as the "Energy-saving and New Energy Vehicle Industry Development Plan (20122020)"(referred to as Plan 2020), and has formulated and implemented multiple stages of fuel consumption

a Corresponding author: zhengtianlei@catarc.ac.cn 
standards. Among them, the "Plan 2020" released in 2012 proposed that "the average fuel consumption of new passenger cars will be reduced to $5 \mathrm{~L} / 100 \mathrm{~km}$ in 2020 , and the fuel consumption of new commercial vehicles will be close to the international advanced level" ${ }^{3}$. The "Medium and Long-term Development Plan for the Automobile Industry" released in 2017 further proposed that "the fuel consumption of new passenger cars will be reduced to about $4 \mathrm{~L} / 100 \mathrm{~km}$ by 2025 , and the fuel consumption of new commercial vehicles will reach the international advanced level" ${ }^{4}$. In 2020, China issued the "New Energy Vehicle Industry Development Plan (2021-2035)", which further proposed that average energy consumption of new battery electric passenger cars reduces to $12.0 \mathrm{kWh} / 100 \mathrm{~km}$ by $2025^{5}$.

\section{The standard system}

\subsection{Overview}

Since 2001, China has strengthened the research on automobile energy-saving standards. Afterwards, the automobile energy-saving standard system has been continuously supplemented and improved. At present, a complete system covering all vehicle types including passenger cars, light-duty commercial vehicles and heavy-duty commercial vehicles has been formed. At present, there are 19 standards in the automobile energysaving standard system, including 6 mandatory national standards and 13 recommended national standards. The automobile energy-saving standard system is shown in Figure $1^{6}$. In terms of standard types, the automobile energy-saving standard system includes four types of standards: basic and general, test methods, limits and indicators, and label standards; from the vehicle power types, it covers gasoline and diesel vehicles, alternative fuel vehicles, hybrid electric vehicles(referred to as $\mathrm{HEV}$ ), battery electric vehicles(referred to as BEV) and fuel cell vehicles(referred to as FCV).

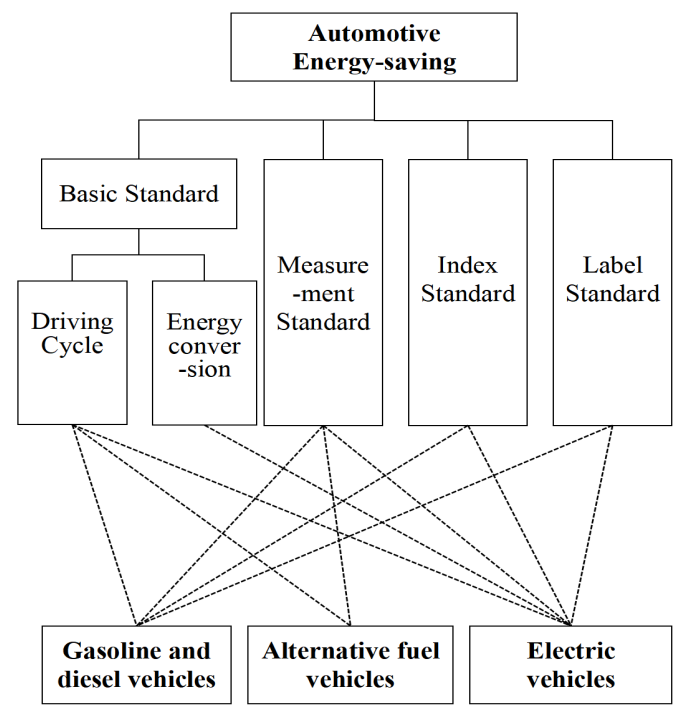

Figure 1. China Automotive Energy Conservation Standard System

\subsection{Status quo of standards in various fields}

Affected by market size and product structure, there are big differences in the priority and system integrity of the energy-saving standards for various types of vehicles in China. Gasoline and diesel vehicles currently still account for the majority of China's vehicle ownership, and have the greatest impact on the overall energy consumption and carbon emissions of the industry. Therefore, standard research on gasoline and diesel vehicles was initiated first, and a complete standard system has now been formed. With the rapid growth of the NEV industry, related energy-saving standards have also developed rapidly. China has successively formulated and completed important standards such as BEV and HEV energy consumption test methods, lightduty vehicle energy consumption labels and BEV energy consumption limits.

\subsubsection{Gasoline and diesel vehicles}

Currently, there are 11 automotive energy-saving standards in the field of gasoline and diesel vehicles. The light-duty vehicle with a maximum design total mass of less than 3.5 tons has formed a complete standard system including fuel consumption test methods, limits, evaluation indicators and labels. The heavy-duty commercial vehicle has completed National standards for fuel consumption test methods and limit values, which have formed a basic fuel consumption standard system. The establishment and implementation of fuel consumption standards for gasoline and diesel vehicles has played an active role in promoting the development and application of automotive energy-saving technologies and improving automotive fuel economy, and has become the technical basis and foundation for government authorities to strengthen and improve automotive energy-saving management.

\subsubsection{Electric vehicles}

Electric vehicles(referred to as EV) include BEV, HEV and FCV. Currently, there are 6 automotive energysaving standards in this field. NEVs are still in the initial stage of industrial development. China has first carried out research on standardizing key energy consumption parameter tests methods, and formulated energy consumption and driving range test methods of $\mathrm{HEV}$, $\mathrm{BEV}$ and FCV. In 2017, the energy consumption labeling standards for light-duty BEV and HEV were formulated and completed. In 2018, in order to further promote the improvement of key technical indicators such as the energy consumption of NEV, China issued the recommended national standard "Electric Vehicle Energy Consumption Limits" (GB/T 36980), which is the first energy consumption limit standard for NEV in the world. 


\subsubsection{Alternative fuel vehicles}

Alternative fuel vehicles such as compressed natural gas(referred to as $\mathrm{CNG}$ ) vehicles are still in the development stage of guidance and incentives, and account for a relatively small proportion of the total vehicle ownership. Therefore, the relevant vehicle energy-saving standards are mainly based on unified measurement methods, and no mandatory fuel consumption requirements are proposed. At present, China has issued the fuel consumption test method standards for CNG vehicles, and completed the industry standard research on methanol vehicle fuel consumption test methods.

\section{Key problems}

\subsection{The test method standards need to be revised and improved}

Formerly, the fuel consumption and energy consumption test method standards of various types of vehicles in China are mainly based on the adoption of foreign standards. Directly adopting foreign driving cycles and test conditions cannot accurately evaluate the actual driving of China's vehicles. The actual fuel consumption is often higher than the test value which makes consumers complains a lot. Therefore, the comprehensive application of new driving cycles such as China automobile driving cycles(referred to as China cycle) is an important development direction of China's automobile energy consumption test method standard system. Moreover, in terms of test condition settings and special test methods, it still needs to be improved. The effects of advanced energy-saving technologies such as idling start and stop, braking energy recovery, highefficiency air conditioning, etc. cannot be fully reflected in the basic test methods. Test methods under special conditions such as low temperature, high altitude, and use of air conditioning are not yet mandatory implementation.

\subsection{The energy-saving standard system for NEV is not yet complete}

EV energy consumption is one of the most important indicators that reflect the technical level and competitiveness of NEV, and it has a direct impact on the driving range. At present, China has issued and implemented a number of energy consumption test method standards for HEV, BEV and FCV. At the same time, China has issued a recommended national standard for energy consumption limits for pure electric passenger vehicles. However, there is still a lack of binding indicators and standards for other types of EV, and a complete and effective energy consumption evaluation and management system has not been established. As China's NEV industry enters the fast lane of development, it is imperative to build a complete NEV energy-saving standard system.

\subsection{Coordinated development of traditional vehicles and NEV}

Starting from the 4th stage fuel consumption standard for passenger cars, China has included NEV in the accounting scope and provided incentives accounting methods and multiples, playing an active role in both reducing fuel consumption and promoting NEV. However, with China's increasing support for NEV and the increasing calls for "ban on the sale of fuel vehicles", automobile manufacturers lack the motivation for traditional energy-saving technology research and development, and generally focus their funds and research on NEV. The production of more NEV to meet the manufacturer's average fuel consumption requirements has affected the improvement of gasoline and diesel vehicle fuel consumption to a certain extent. In the future, it is necessary to further build a more complete and balanced standard evaluation system to achieve the coordinated development goals of traditional fuel vehicles and NEV.

\section{Development prospects}

\subsection{Taking carbon peaks as the overall goal to formulate of energy-saving standards}

In the next stage, the automobile energy-saving standards will take the carbon peak by 2030 as the overall development, make overall plans for the energysaving development path of traditional fuel vehicles and NEV, carry out the total energy consumption and carbon emission calculations of the automobile industry, and set energy-saving targets of passenger cars, light-duty commercial vehicles, heavy-duty commercial vehicles and other vehicle types from 2025 to 2030, and build a vehicle energy-saving standard system with stricter indicators and more complete testing methods. Carry out studies on mandatory standards such as the 6th stage fuel consumption standards for passenger cars and the 4th stage fuel consumption standards for commercial vehicles to support government energy-saving management, guide consumers to buy energy-saving vehicles, and ensure reaching the goal of automobile energy saving of the next stage in China.

\subsection{Further improve the automotive energy- saving standard system with the focus on NEV}

Support the national strategy for the development of $\mathrm{NEV}$, and further improve the vehicle energy-saving standard system in accordance with industry and technological development trends. Improve the integrity of the NEV energy-saving standard system, promote the formulation of energy consumption indicator standards for all types of NEV such as BEV, and further expand the full life-cycle and hydrogen life-cycle energy conversion methods, and establish a comprehensive automobile energy-saving standard system composed of different types of standards such as test methods, limits, labels, and basic and general standards. 
Comprehensively revise and improve the test method standards, and complete the replacement of the original driving cycles with new cycles such as the China cycles. Carry out research on off-cycle technology standards such as idle start and stop, braking energy recovery, high-efficiency air conditioning, and guide the further application of special test procedures such as low temperature and high altitude, forming a comprehensive test method system combining "basic test + special test" . Strengthen the applicability of test method standards to intelligent connected vehicles, and revise driving cycles, test conditions and procedures in accordance with the characteristics of autonomous driving.

\subsection{Improve energy consumption labeling standards with serving consumers as the core}

In order to make vehicle energy consumption information more transparent and guide consumers to purchase advanced vehicle types with low fuel and energy consumption, China has formulated and implemented the mandatory national standard "Lightduty Vehicle Energy Consumption Labeling" (GB 22757) which become one of the important references for consumers to purchase vehicles. In the next stage, on the basis of revising and improving the test method standards, the revision of the series of automobile energy consumption labeling standards will be fully initiated to supplement the new driving cycles such as the China cycles and the test results under special conditions of use, and provide consumers with the actual energy consumption information of vehicles and guides the green consumption of the society.

\section{Summary}

Since the establishment of China's automobile energysaving standard system, it has played an important role in promoting the development of energy-saving emission reduction technologies and reducing carbon dioxide emissions. The proposal of China's overall goal of peaking carbon by 2030 puts forward new requirements for the next stage of automobile energy-saving standards. This article comprehensively introduces the current situation of China's automobile energy-saving standard system and existing problems at this stage, and puts forward future development priorities based on industrial development trends, and comprehensively promotes the construction of automobile energy-saving standard systems in areas such as NEV with the overall goal of carbon peaking to fully assist the achievement of the carbon peak goal of the automotive industry.

\section{References}

1. DieselNet. (2021) EU: Cars: Greenhouse Gas Emissions. https://dieselnet.com/standards/eu/ghg.php.

2. DieselNet. (2021) Japan: Fuel Economy. https://dieselnet.com/standards/jp/fe.php.
3. State Council. (2012) Energy-saving and New Energy Automobile Industry Development Plan (2012-

2020).http://www.gov.cn/gongbao/content/2012/con tent_2182749.htm

4. MIIT and etc. (2017) Medium and long-term development plan for the automobile industry. http://www.gov.cn/gongbao/content/2017/content_5 230289.htm

5. General Office of the State Council. (2020) New Energy Automobile Industry Development Plan (2021-2035).

http://www.gov.cn/gongbao/content/2012/content_2 182749.htm

6. Zheng, T.L.,Wang, Z., Bao, X., Liu Z.C., Ji, M.X., Liu, S.H. (2020) Research on automobile energysaving standard system based on new driving cycles. China Automobile, 2020(09): 44-48. 